\title{
Pioneras españolas en el mundo del tebeo y su articulación múltiple de lo femenino
}

Este ensayo profundiza en la labor de creadoras españolas nacidas en la década de los treinta del siglo pasado y lo que significó abrirse paso en una época dominada por valores profundamente machistas. Se analizan algunas historietas de Isabel Bas Amat (n. 193I), creadora de la serie Ana-Emilia y su familia. Presenta un panorama de otras autoras como María Pascual (193320II), que fue la maestra del cómic romántico, y Carmen Barbará (n. 1933), conocida por dibujar el personaje de la serie de la reportera Mary "noticias". El artículo cierra reflexionando sobre la labor de Purita Campos (n. 1937), conocida por el personaje de Esther.

Palabras clave: Historietas españolas, Isabel Bas Amat, Carmen Barbará, María Pascual, Purita Campos

This essay elaborates on the work of Spanish women artists born in the nineteen thirties and what it meant to blaze a trail in the field during an era dominated by deeply-rooted machista values. It offers an analysis of selected comics by Isabel Bas Amat (b. I93I), creator of the series Ana-Emilia y su familia. It also broaches the work of other women authors such as María Pascual (1933-20II), master of romantic comedies since the mid-fifties and throughout the seventies, and Carmen Barbará (b. 1933), known for drawing the main character of the reporter series, Mary "noticias." It closes with a reflection on the work of Purita Campos (b. 1937), known for the character of Esther.

Keywords: Spanish comics, Isabel Bas Amat, Carmen Barbará, María Pascual, Purita Campos

Los estudios generalistas, tanto académicos como divulgativos, sobre la producción femenina del cómic fueron un fenómeno aislado en la España del siglo pasado. No ha habido, hasta muy recientemente, una cohesión de autoras o críticos que se agruparan para generar respuestas conjuntas y trazaran genealogías que dialogaran con sus trabajos y trayectorias. Este

REVISTA CANADIENSE DE ESTUDIOS HISPÁNICOS 43.I (OTOÑO 2OI8) 
ensayo sirve de guía para introducir los diferentes estudios que ayudaron a divulgar el cómic femenino a partir de la década de los sesenta, y analiza con ejemplos el peso que tuvieron autoras claves como Isabel Bas Amat, Carmen Barbará, María Pascual o Purita Campos a la hora de representar con sus cómics la época en la que los crearon.

En Estados Unidos, la labor reivindicativa de la voz femenina vino de la mano de las propias autoras de cómics que, a mediados de los setenta, fueron tomando agencia. Quizás la artista que más se ha preocupado por elaborar una genealogía clara del siglo veinte sea Trina Robbins. Esta autora estadounidense fue una de las pioneras del movimiento underground femenino y vivió de primera mano la transformación discursiva del cómic hacia vertientes adultas que expresaban problemáticas y reivindicaciones feministas. Dentro de estas reivindicaciones feministas, estaba también la idea de recuperar el pasado y trazar genealogías donde aparecieran las voces femeninas que habían abierto el espacio creativo de las autoras. Robbins fue consciente de que había que reivindicar la historia de los primeros cómics realizados por autoras y dar a conocer su estilo y sus tramas para ampliar el canon y ofrecer un panorama completo del mundo del cómic. ${ }^{\mathrm{I}}$

En la década de los noventa, Robbins publicó dos libros de corte historiográfico que establecieron un importante punto de partida para los estudiosos del campo. El primero, A Century of Women Cartoonists, publicado en 1992, se centraba en la producción femenina norteamericana desde finales del siglo diecinueve hasta comienzos de los noventa. Su discurso era sobre todo de recuperación historiográfica de las autoras y sus trabajos, pero se preocupaba también por reflexionar sobre las dificultades a las que se fueron enfrentando en una industria predominantemente masculina. En 1999, Robbins publicó From Girls to Grrrlz: A History of Women's Comics from Teens to Zines, continuando de este modo con sus esfuerzos por recuperar voces y trazar genealogías que ayudaran a explicar la evolución y transformaciones del cómic realizado por mujeres. La autora parte del espacio adolescente al que estaban destinados los primeros personajes y series, para luego ir describiendo los cambios en el estilo y el tipo de audiencia. El cómic realizado por mujeres también alcanza su propia mayoría de edad y busca lectoras adultas y conscientes que vean en las tramas de los fanzines el reflejo de sus propias reivindicaciones.

Cuando se estudia el caso español, sobresalen las investigaciones pioneras del profesor Juan Antonio Ramírez, autor del ensayo académico $E l$ cómic femenino en España (1975). Este catedrático e historiador del arte fue uno de los primeros académicos que abrieron campo en el estudio académico de los cómics, llevando a cabo la primera tesis doctoral sobre la historieta española de posguerra. Sus estudios destacaron cómo la 
historieta femenina en España se apoyaba en una atención a la mujer como público consumidor. Josune Muñoz, en el ensayo recogido en las actas de su ponencia de 2orr sobre la historia del cómic femenino en la Universidad de San Petersburgo, destacaba, sobre todo, la minuciosa labor crítica de Juan Antonio Ramírez y su estudio de 1975 (2). Por otra parte, Muñoz lamentaba que las publicaciones de divulgación más recientes que habían aparecido a finales del 2010, como Chicas de cómic de Guillem Medina o El tebeo femenino de la documentalista Marisa Mediavilla, fueran sobre todo ejercicios de recuperación generalistas carentes de intención crítica (Campos, Presentación 3-4). Estos libros, por su intención editorial comercial, apelaban sobre todo a las lectoras que sentían añoranza y también a muchos lectores que buscaban en ellos las referencias a sus lecturas de niñez y adolescencia. El propio Guillem Medina, en una entrevista en 20 Io que le hizo Jesús Jiménez para rtve.es, confesaba que su libro de homenaje a los personajes femeninos era para nostálgicos, que estaba pensado para un público muy concreto y que quería que "a la gente le entrara por los ojos. Por eso era tan pop, con tanto colorido". En esa misma línea estaría el reciente volumen de Ruth Bernárdez, Las chicas son guerreras (2018), que recoge un panorama descriptivo de la producción del cómic femenino de la década de los setenta y ochenta. Todos estos libros sirven para trazar un mapa historiográfico inicial de los materiales que aparecieron y ayudan a los investigadores a localizar dicha producción. El estudio detallado de viñetas, páginas e historietas, siguiendo el modelo de análisis que ya propuso Umberto Eco con su "Lectura de Steve Canyon" - ensayo recogido en su libro ya clásico Apocalípticos e integrados - está todavía por construir en el espacio académico de los cómics femeninos en España. Los divulgadores se preocupan sobre todo por acumular el máximo de información y ofrecer esos datos que sitúan a autoras y obras, y no incluyen análisis detallados de ejemplos concretos en sus propuestas editoriales. ${ }^{2}$

Llenando esta laguna de escasez de textos y estudios sobre las creadoras, en 2013 surge en España el Colectivo de Autoras de Cómic (AC) para luchar por la igualdad real y efectiva en el espacio profesional de la historieta. Volver a indagar, estudiar y divulgar el pasado de las autoras pioneras del siglo veinte forma parte de la labor de este dinámico colectivo capitaneado por la estudiosa Elisa McCausland y la creadora Carla Berrocal. Este grupo, además de comprometerse con el talento y el potencial de las nuevas generaciones de autoras, quiere recuperar y visibilizar esas creadoras del siglo pasado que quedaron fuera del discurso masculino hegemónico de su época. Desean así abrir el canon del pasado y el presente para educar a todos los lectores en una genealogía más rica y completa. Para fortalecer el proyecto crearon el Premio Honorífico del Colectivo Autoras de Cómic como una forma de reivindicar y divulgar el perfil creativo de estas 
grandes figuras femeninas. El premio arrancó en 2013, y Núria Pompeia (193-2016) fue la primera autora celebrada y reivindicada por el colectivo por su labor como humorista gráfica en las revistas Triunfo, Dunia, Por favor y Cuadernos para el diálogo. Pompeia también tuvo proyección internacional en las revistas Charlie Hebdo, Brigitte y Linus. Su perfil combinaba el talento del humorismo gráfico con la labor editorial. Fue además redactora jefa de las revistas Por favor y Saber, y cronista cultural en La Vanguardia. Colaboró como guionista en televisión y dirigió el centro cultural Casa Elizalde. Toda su vida estuvo firmemente comprometida con la cultura, y en sus últimos años tuvo importantes reconocimientos: en el 2000 fue condecorada con la Medalla de Oro al mérito artístico de la ciudad de Barcelona, y en 2007 con la Cruz de San Jordi de la Generalitat de Cataluña. Elisa G. McCausland, en su artículo en línea para la revista Pikara Magazine, destaca que Pompeia, en su "primer trabajo, Maternasis (1967), cuestionaba las asignaciones de género en lo que a ser madre se refiere". En sus diferentes obras sobresale el feminismo de las mujeres que optan por disfrutar de la vida y reivindican su existencia fuera del matrimonio. Además combinó la viñeta editorial con el columnismo de opinión. Otras de sus obras son Y fueron felices comiendo perdices ... (1970) o La educación de Palmira (1972), trabajo que realizó mano a mano con Manuel Vázquez Montalbán, inicialmente por entregas, para la revista Triunfo en la década de los sesenta.

En 20I4, el Colectivo de Autoras de Cómic decide premiar, en su segunda convocatoria, la trayectoria de Rosa Galcerán (1917-2015). Esta autora ha sido reconocida por su trabajo en el ámbito de la historieta comercial y por participar en las primeras obras de animación que se hicieron en la década de los cuarenta en España. Formó además parte del equipo de la revista Mis Chicas, uno de los primeros tebeos femeninos de la posguerra española que apareció entre I94I y I950, que tuvo 407 números y fue fundado y dirigido por la carismática Consuelo Gil.3 Esta editora lideró un entramado clave de revistas para el público infantil, como la mencionada Mis Chicas, la revista Chicos o la revista Chiquitito. Fue además considerada un modelo intelectual de editora por su visión tenaz, su pragmatismo organizativo y su profunda empatía con las inquietudes lectoras de los niños. Pudo intuir el papel que jugaría la cultura de masas y del entretenimiento, y la importancia de mantener el diálogo con el ámbito de la cultura literaria. En su equipo de colaboradoras, destacarían una jovencísima Gloria Fuertes, formidable poeta para adultos y escritora infantil, y la narradora Borita Casas, conocida por sus libros juveniles de Antoñita la fantástica. 4

En 2015, el Colectivo de Autoras de Cómic, continuando con su labor de recuperación de grandes autoras pioneras, otorga el premio en su tercera 
convocatoria a la barcelonesa Isabel Bas Amat. Esta autora veterana nació en I93I, y es una de las pocas mujeres que trabajó para la revista juvenil de historietas TBO. Otras de las autoras fueron Rosa Segura y Teresa María Pons, quienes, además de trabajar como secretarias, colaboraron con textos y guiones en algunas secciones. También destacan los trabajos de María Urda y María Ángeles Sabatés, hijas de Manuel Urda y Ramón Sabatés, respectivamente, colaboradores históricos de la revista.

La revista $T B O$ fue fundada hace un siglo, en I917, y ha sido tan carismática que, como se explica más adelante, en sus tres letras está el origen del término español "tebeo". Entre I967 y 1983, Isabel Bas Amat participó en más de doscientos números del TBO con la serie Ana-Emilia y su familia y otras historietas y piezas de humor. En la década de los cincuenta, colaboró en varios proyectos con la Colección Margarita de la editorial Favencia, también en Los cuentos de la Abuelita, y en la serie Matildita, el terror del barrio, ambas de la editorial Toray. La década de los sesenta es enormemente productiva para Isabel Bas Amat. Entre r965 y I967, colaboró con la editorial Bruguera y las revistas Tío Vivo, Din Dan y Capitán Trueno. Y, de 1966 y I967, realizó la serie Els Yeyés para la revista L'Infantil Tretzevents y la serie Pitusin y sus amigos para la revista Davy y su Fiel Roy de la editorial Cliper.

La serie Matildita, el terror del barrio, que apareció en 1957 en Ediciones Toray, mostraba viñetas con mucho humor en las cuales la niña Matildita, con sus dos trenzas rubias, era coqueta y respondona y hacía todo tipo de travesuras, tanto en la escuela como en la calle. Era tan atrevida que discutía con los policías o se quería colar en el circo, y enredaba a sus amigas para que la ayudasen a llevar a cabo todo tipo de planes. Las publicaciones de Ediciones Toray mostraban modelos de niñas muy variados dentro de sus colecciones de revistas juveniles femeninas. Esa gran producción de cabeceras y números facilitaban que se eludiera la censura. Al ser material popular para niñas, la censura no era tan rígida como con las revistas para adultos o los libros literarios. Por otra parte esta serie competía con otras donde los modelos de mujer eran más tradicionales. Además, el humor de Matildita estaba en sintonía con el de los niños maleducados de las comedias costumbristas del franquismo. En la película La gran familia de I962, dirigida por Fernando Palacios y producida por Pedro Masó, aparecen una variedad de niños, algunos sumamente revoltosos y gamberros. En cierta medida, la tradición de los niños de la novela picaresca perdura y se proyecta en los nuevos espacios de la cultura popular. Matildita contrasta con el personaje de Ana Emilia, una niña también rubia que Bas Amat creó diez años después para la revista TBO. Matildita es más maleducada y atrevida, mientras que Ana-Emilia representa a un tipo de niña dulce y bienintencionada. En este caso, el modelo se asociaría a la niña que 
representan las películas de la joven actriz y cantante Marisol, que tuvieron tanto éxito en la década de los sesenta.

La primera entrega de la serie Ana-Emilia y su familia apareció el 23 de junio de 1967 en el TBO número 504. Por ese entonces, la revista $T B O$ ya estaba en su segunda época numerada que había comenzado en 1952 y tenía muchísima popularidad con tiradas pico de más de trescientos mil ejemplares. Tal era el impacto de la revista que, en 1968, un año después de su quincuagésimo aniversario, la Real Academia Española de la Lengua incorpora y reconoce el término "tebeo". La voz aparecerá insertada a partir de las ediciones impresas del diccionario de 198 r. 5 En la actualidad la entrada de la palabra "tebeo" en el diccionario de la RAE indica precisamente su origen en el TBO, aclara que era el "nombre de una revista española fundada en 1917" y la define como nombre masculino con dos acepciones: como "publicación infantil o juvenil cuyo asunto se desarrolla en series de dibujos" o como "serie de aventuras contada en formas de historietas gráficas" ("tebeo").

Isabel Bas Amat comenzó a colaborar en la revista en uno de sus momentos de mayor fuerza y reconocimiento popular. Pero por aquel entonces, casi no había mujeres creadoras trabajando en el proyecto, por lo cual el contenido de sus trabajos podía marcar una importante diferencia en el imaginario de los pequeños lectores. Entre las series que hacían los autores hombres destacaban, por ejemplo, La familia Ulises de Benejam, Josechu "el vasco" de Joaquim Muntañola oJoaquinete y su chupete de Esbert.

La serie de Ana-Emilia y su familia constaba de entregas cerradas de una página de humor autoconclusivo. ${ }^{6}$ Son piezas que, al ser analizadas con detenimiento, muestran los modelos de feminidad imperantes en la sociedad del momento, hecho que ciertamente queda muy bien recogido en las películas de Marisol. Su primera entrega en blanco y negro, que apareció en el TBO número 504, presenta una página de seis viñetas con una cartela superior en la que se recoge el título de la serie. En la primera viñeta descubrimos a Ana Emilia, una niña rubia con diadema, en primer plano agarrando el palo de una fregona mientras saluda a su padre que llega del trabajo con traje y cartera. El bocadillo con sus palabras nos pone en situación: "Hola, papá, no pises muy fuerte, estoy fregando". Parece que el padre no se da cuenta y la ignora. En la siguiente viñeta será su hermano el que pase leyendo un tebeo sin prestar atención. Este detalle evidencia una diferencia clave en el uso del espacio doméstico por parte de los chicos, que, por otro lado, parecen ser los que están autorizados a disfrutar del entretenimiento de los tebeos. El plano entero nos muestra la fregona, el charco con agua, el cubo y a Ana Emilia molesta mientras friega con el trasiego de gente: “¡Ahora tú! ¿Es que os habéis puesto de acuerdo?”. En la tercera viñeta es el perro Bolita, con las patas llenas de barro, el que 
desespera a la pobre Ana Emilia que tanto se está esforzando por dejar el suelo brillante. La cuarta viñeta introduce otra vez al hermano de la niña leyendo el tebeo y sin prestar atención a los esfuerzos de su hermana por dejar el piso limpio. Esta vez, Ana Emilia le grita con fuerza a su hermano: “¿¿tra vez?! ¡Estoy fregandooo!”. La penúltima viñeta retrata a la protagonista corriendo para buscar algo que impida la continua intromisión de personas en los lugares que está fregando. La viñeta de cierre muestra a la madre y al hermano de Ana Emilia contemplando con sorpresa una señal de prohibido de la calle cerrando el acceso a la sala que la protagonista continúa fregando. El humor se construye con la tenacidad y el ingenio de Ana Emilia, quien debe buscar estrategias para terminar sus labores. En este caso, sorprende el contraste familiar en el que padre y hermano ignoran los esfuerzos de la niña por mantener limpio el suelo y generan, por otra parte, que ella tome la decisión de subirse una señal de "prohibido el paso" de la calle. Los códigos de convivencia reflejados en la historieta nos muestran una sociedad patriarcal profundamente machista. Indican que el espacio de interacción familiar de las niñas está construido en torno a las labores de limpieza del hogar. Sin embargo, el hermano ni participa ni empatiza con las labores de su hermana, por lo que podemos ver que están recibiendo una educación desigual. Las niñas del franquismo se preparan para ser amas de casa, para adueñarse del hogar como sujetos sumisos en estructuras patriarcales.

Elisa McCausland, en su introducción a la entrevista que hizo a Isabel Bas Amat para Tebeosfera, explica cómo esta serie, la más longeva de su trayectoria, apareció en la época en la que el TBO estaba dirigido por Albert Viña. Fue concebida como indica McCausland, como "una serie de aventuras cuyo humor aparentemente blanco se encargará de poner sobre la mesa ciertas contradicciones tanto familiares como de la sociedad, pero siempre desde una perspectiva optimista". Esa idea de mostrar las contradicciones sociales y familiares, ya está presente en la primera entrega de la serie en la que la niña Ana Emilia es la que friega y sufre además la indiferencia descuidada de su padre y su hermano. Al subir una señal de "prohibido el paso" de la calle se crea el humor, y se muestra la capacidad de la protagonista para enfrentarse a la indiferencia irrespetuosa y seguir con su trabajo. En ningún momento, sin embargo, se cuestiona que su hermano no esté ayudándole a fregar. El humor blanco celebra el carácter resolutivo de la niña que se las ingenia para acotar su territorio de trabajo e impedir que se lo vuelvan a manchar. Ana Emilia desarrolla una inteligencia resiliente que convive con el orden patriarcal, al que evita enfrentarse de manera radical. Trata de buscar estrategias que le permitan mantener su espacio limpio. 
En la entrevista a Isabel Bas Amat, Emilia McCausland contextualiza el lugar de las autoras en la década de los cincuenta y sesenta. Isabel Bas Amat es muy clara y le explica que en su época ella "no tuvo relación con las demás autoras de cómic" (McCausland). Llegaba para entregar los encargos y no coincidía con nadie. Además, la autora fue autodidacta gracias a su afición a leer tebeos e historietas que copiaba desde niña. Cuando comenzó a trabajar para la revista $T B O$ su director, Albert Viña, fue quien le encargó una historieta de seis viñetas de página autoconclusiva que fuera semanal. El personaje de Ana Emilia está inspirado en la hija del director, y la serie duró once años como historieta fija. En el proceso de elaboración de las historias Isabel Bas Amat primero pasaba el boceto al director Viña para que lo aprobara, y este en alguna ocasión le pedía que cambiara alguna cosa o se quejaba por algunos detalles. La propia autora reconoce que a veces se "pasaba un poco" en hacer que la familia quedara bien parada porque "era la familia de los jefes, y no era cuestión de que aparecieran demasiado ridículos o poco dignos". Tal vez por eso muchas de las tramas de esta niña Ana Emilia fueron tan convencionales y ofrecían un modelo de familia muy plano y alejado de la niña Matildita que había inventado una década antes.

En el TBO número 534 del I9 de enero de 1968 , vemos al personaje de Ana Emilia haciendo otras tareas domésticas. En esta ocasión aparece en la primera viñeta alistándose para salir a la compra con el carrito y diciéndole a su perra Bolita, que no la puede acompañar. En la segunda viñeta, mientras su madre le da el dinero y la lista de la compra, la perra se mete en el carrito sin que nadie se dé cuenta. En las dos siguientes viñetas Ana Emilia comprará salchichas, chuletas y jamón. Al llegar a la casa la perra saldrá del carrito de la compra sin que ni la niña, ni la madre, que está cocinando, lo noten. En la última viñeta vemos como Ana Emilia y su madre observan el carrito vacío desconcertadas mientras que en un primer plano aparece la perra Bolita dormitando con la panza llena. De nuevo se observa esa construcción familiar en la que el mundo de las mujeres está asociado a las labores del hogar. Ana Emilia es la que ayuda a su madre en la cocina y va a hacer la compra al mercado. Esta historieta muestra un tipo de sociedad machista donde los roles del hombre y la mujer están totalmente diferenciados. Es decir, la mujer debía dedicarse a las labores del hogar, preocupándose por la preparación de las comidas y por la limpieza de la casa, mientras que los hombre se dedicaban a todo tipo de labores intelectuales, políticas o empresariales.

En la muestra del $T B O$ número 537, vemos otra vez a Ana Emilia como una niña emprendedora que decide hacer un abrigo a su perra Bolita cortando unos trozos de paño de un retal que encuentra en la casa. Otros dos perros del vecindario se convierten en candidatos a tener abriguitos diseñados y confeccionados por Ana Emilia. Sin embargo, cuando aparece 
su madre, la niña descubre que esa tela que utilizó para abrigar a los perros estaba destinada a un abrigo para ella misma. En la última viñeta, veremos a Ana Emilia sentada en las escaleras de la puerta de su casa, pasando frío y pensando en que se ha lucido con su ocurrencia, mientras que los tres perros abrigados la contemplan con ojos amorosos. Ana Emilia sale perjudicada por su iniciativa de fabricar abrigos para perros sin consultar a su madre sobre el retal de tela que encuentra en la casa. Nuevamente, vemos el tebeo reflejando cómo saber coser forma parte de la esfera femenina del hogar. Ana Emilia, según este discurso, es una niña lista, con iniciativas y buena disposición para las tareas típicamente femeninas (limpiar, comprar comida o coser), aunque es cierto que, a lo largo del tiempo, Isabel Bas Amat fue añadiendo otras características más progresistas al personaje de la niña. Por ejemplo, en ella Bas Amat proyectó su propia pasión por los deportes. Por eso hay historietas donde la niña escala, juega al tenis de mesa o nada. Mirando a su trayectoria en retrospectiva, Isabel Bas Amat todavía reivindica un estilo tierno, limpio y pedagógico para aquellas historietas destinadas a los niños. Parecería como si el estilo de las historietas de Ana Emilia priorizara un continuismo pedagógico y conformista con los espacios de representación tradicionales. Esto es probablemente debido a que para subsistir colaborando en TBO había que amoldarse a las demandas ideológicas de sus directivos.

El espacio para las lectoras niñas y adolescentes lo ocuparían las historietas y las ilustraciones de la también barcelonesa María Pascual (1933-20II). En su caso se aprecia una evocación de la feminidad romántica. Las niñas de las historietas de Bas Amat crecen para convertirse en mujeres impregnadas por el romanticismo dependiente de las figuras masculinas. En 2015, la editorial Planeta Agostini recuperó los mejores relatos infantiles que María Pascual había ilustrado durante las décadas de los sesenta y setenta. Esa recuperación editorial significó un reconocimiento de la importancia que tuvo la cultura popular en la educación sentimental de las lectoras de su época. Sobre este aspecto ha profundizado Carmen Martín Gaite en su libro Usos amorosos de la postguerra. En ese libro que le valió el premio Anagrama de ensayo de 1987, Martín Gaite hace un análisis de las revistas del corazón $\mathrm{y}$ otros artefactos culturales que marcaron el perfil educativo de las mujeres y las formaron para aparentar conformidad con sus roles femeninos. Explica cómo estas mujeres, sirvientas del hogar, crecían sometidas a estructuras familiares de dependencia romántica donde su única misión era enamorarse, casarse y cuidar de su esposo y sus hijos.

La obra de María Pascual está asociada al género romántico. Sobre todo, las piezas que hizo para las colecciones femeninas de la editorial Toray, como Rosas Blancas, Serenata, Susana o Guendalina, y que fueron apareciendo a lo largo de la década de los cincuenta y sesenta. El 
romanticismo que rezumaba de los guiones de aquellas historietas, implicaba una construcción de la feminidad clásica de dependencia masculina en la cual las mujeres construían y definían su existencia en torno al enamoramiento y al matrimonio como el gran logro personal, como bien indica Carmen Martín Gaite en sus escritos. El modelo estético y la finura del dibujo de María Pascual estaba ligado a la publicidad de la moda francesa, por lo que es percibida como una mujer adelantada a su época que introduce elementos modernizadores. El modelo de mujer que aspiraba al matrimonio y creía en el amor ideal no era el ángel del hogar tradicional; eran mujeres independientes, refinadas y modernas que en ese proceso de elegir y enamorarse del hombre ideal relataban sus sentimientos y definían su propio lugar. El ascenso de las clases medias y la influencia de modelos del exterior que penetraban a través de las revistas o el cine fraguaron interesante líneas estéticas y matizaron el perfil de la mujer que, aunque aspiraba a enamorarse y casarse, quería establecerse en otras esferas profesionales.

Esa idea de mujer independiente fructificó en una serie titulada Mary "noticias", que duró nueve años, de 1962 a 1971, y fue carismática por la fuerza de su protagonista. Los guiones eran de Ricardo Acedo Lobatón (quien firmaba como Roy Mark) y contaban con el inolvidable y sugerente dibujo de la autora barcelonesa Carmen Barbará. Esta autora fue coetánea y nació el mismo año que la antes mencionada María Pascual. En una entrevista de 20I4 con la ilustradora Carmen Barbará, la periodista Catalina Gayá celebraba la revolucionaria imagen de las mujeres en el tebeo con ese personaje de una reportera televisiva como Mary "noticias". Lo curioso es que la propia Barbará trataba de contextualizar las circunstancias del momento sorprendida del impacto posterior: "Yo creo que exageran un poco", explica Barbará: “A mí, me daban el guión y yo ni conocía al guionista. A Ricardo Acedo, el primer guionista, lo conocí al cabo de 50 años" (citado en Gayá). Mary "noticias" surge porque un día Josep María Arman, el editor de Ibero Mundial, le pide a la autora que haga un personaje. Barbará lo explica con mucha naturalidad: "Me la imaginé y salió así: le ponía los vestidos que diseñé para mí misma. Proponía que hicieran algo que pasara en China o en Japón y Mary se iba a donde fuera para resolver un misterio" (citada en Gayá). Según la autora no era la historia romántica al uso porque había misterios. Efectivamente, el personaje de Mary "noticias" era una periodista televisiva de la sección de sucesos. Su novio Max, un joven y atractivo abogado, esconde la identidad de un detective llamado Bruma bajo unas gafas negras y una barba postiza. Como una sombra salvadora, y sin que Mary realmente se dé cuenta, interviene, protege y la ayuda en los diferentes casos a los que se enfrenta la reportera. Barbará explicaba que no era una historieta romántica típica porque había acción, se resolvían 
misterios y tenía a su novio, Max, con el que viajaba a París: "Max se disfrazaba y era Bruma, que era quién la sacaba de los líos. Había tensión, pero Mary siempre fue fiel a Max" (citado en Gayá). Es decir, se jugaba con la ambigüedad. Mary desconocía la verdadera identidad de Bruma, y no se daba cuenta de que era su novio, Max. La censura se fijó en este cómic porque, según Barbará, dijeron que Mary "noticias" era una mujer muy suelta y se preguntaron “ ¿No tiene familia?”, y esto les obligó a "representar que era Navidad, y que Mary iba a su casa. La censura calló y todo continuó igual" (citada en Gayá).

Cuando se le pregunta a Barbará sobre el final de la serie relata que su editor Josep María Arman le "dijo que no era necesario que dibujara el siguiente guión" (citada en Gayá). Para Barbará fue un alivio, porque tenía un ritmo durísimo de trabajo y así se lo indica a la periodista que la entrevista: “¿Sabe lo que es dibujar cada semana más de 50 viñetas y una portada?" (citada en Gayá). Barbará con esta respuesta le indica a la periodista que entró en la dura profesión de la ilustración de lleno y que la presión y carga de trabajo era desmesurada. Sin embargo, demostró con creces que estaba a la altura de sus compañeros.

Antoni Guiral destaca la importancia de Mary "noticias" y explica cómo estos tebeos de los años sesenta presentan "como protagonistas a chicas con profesiones más 'liberales' o 'modernas"' (I4), y pone como otro ejemplo, la serie Lilian, azafata del aire, de Ricardo Acedo, Enric Badía Romero y Miguel G. Esteban, que apareció entre 1960 y 196r. Esta misma reflexión sobre las importantes transformaciones sociales que evocan los tebeos de chicas las hace Antonio Martín, quien además señala 1957 como la fecha en la que se cambian los comportamientos y aspiraciones sociales. Antonio Martín, en su artículo "Desde la historieta clásica para niñas a Mary 'noticias"', asocia las transformaciones a "los nuevos planes de desarrollo con los que se quería relanzar materialmente al país". Es decir, la apertura económica tendrá una repercusión social que implica una "evolución sociológica". Este cambio se va a reflejar "en las aspiraciones de la mujer, que ya no quiere ser lavandera, costurera, planchadora, ni tampoco dependienta u oficinista, para ganarse la vida. Ahora los modelos y los roles que se proponen a las niñas y a las jovencitas desde los tebeos son: azafata, modelo, periodista, cantante, médico, escritora, abogada, arquitecto, pintora ... o bombero" (Martín). Juan Antonio Ramírez ya destacaba, en su estudio pionero de 1975, cómo en la década de los sesenta se introduce el personaje femenino con personalidad y carácter definido, copiando de este modo la característica fundamental del tebeo de aventuras para chicos. Los tres personajes femeninos fijos más importantes serían las ya mencionadas Lilian, la azafata del aire y Mary "noticias", a las que se suma Belida, aventuras de una 
secretaria. Las tres son reflejos de nuevas profesiones que ofrecen otros parámetros de aspiraciones y expectativas vitales.

En el caso de Lilian y el de Mary, sus ocupaciones están "aureoladas por la fascinación de la fama, la belleza, la atracción de los viajes a lugares exóticos, o la resolución de conflictos policiacos" (Ramírez 97). La acción se construía en torno a tramas en las que se enfrentan a "espías y bandidos al mismo tiempo que cumplen puntualmente sus tareas profesionales" (97). Pero Ramírez destacaba importantes diferencias. Así puntualiza que el personaje de Mary "noticias" ya lo había dibujado Carmen Barbará y que dicha ilustradora era muy conocida entre "las aficionadas". Señala de este modo el ámbito de lectoras femeninas que la seguía, y buscaba piezas de cómics que estuvieran dirigidas a ellas y con las que pudiesen identificarse. Al definir el estilo de la autora, Ramírez era bastante condescendiente, pues lo explicaba como una simple evolución "de los tebeos maravillosos y exótico-sentimentales, hasta llegar al sentimentalismo próximo" (97).

El dibujo de Barbará que nada tenía que envidiar al de los ilustradores hombres de su época, era etiquetado por el estudioso como "sentimentalista", sin profundizar en sus matices, trazos, encuadres o ritmos gráficos secuenciales. Desde la perspectiva de Juan Antonio Ramírez, quien leía y diseccionaba los materiales con la mirada de mediados de los setenta, este cómic "no era demasiado realista y duro: sus tipos siguieron conservando algo de esa blandura ñoña de épocas anteriores que tanto encantaban a las lectoras" (97). Es decir, lo femenino se asociaba a una lectora blanda y ñoña porque "Mary aparecía con modelos un tanto cursis y un rostro estereotipado de mujer-muñeca" (Ramírez 97). La interpretación de Ramírez estaba marcada por un prejuicio inconsciente contra las lectoras, ya que no se daba cuenta de los matices que tenían como adolescentes en su propio espacio de edad. El crítico no se ponía en el lugar de las jóvenes, ni razonaba lo que les podía ofrecer el cómic dibujado por una mujer, más allá de lo que él veía como la equivalencia "blandita" de los discursos de aventuras de los clásicos masculinos. La dualidad secreta de Max, el novio de Mary, que se esconde bajo la personalidad de Bruma generaba un inquietante dilema en la protagonista que sentía una enorme atracción por aquel misterioso desconocido llamado Bruma que siempre le ayudaba. Para Juan Antonio Ramírez, este juego de la ambigüedad era un conflicto que "podría ser también una representación del padecimiento de muchas lectoras (tensión entre el ideal masculino 'cultural' y el 'natural' entre lo 'permitido' y lo 'prohibido', etc.)" que "se resuelve satisfactoriamente porque todas las consumidoras saben que Max y Bruma son la misma persona" (98).

Así el estudioso reivindicaba con mucha ironía al héroe Max-Bruma porque según él, el papel de la reportera era en realidad "asistir admirada" 
a las hazañas del hombre misterioso y "en todo caso, colaborar al éxito desde un puesto secundario" (Ramírez 98). Este modelo de personaje marcado por la ambigüedad y la personalidad secreta ya había sido construido en las tramas del carismático y archiconocido personaje de Superman. El superhéroe, escondido bajo la identidad de Clark Kent, desarrollaba su doble relación con la reportera Lois Lane para delicia de sus seguidores. Pero, en este caso, la serie española estaba destinada a las lectoras y tenía, según el crítico, numerosas carencias que trataba de compensar con un tono falsamente avanzado: "la serie, insertándose aparentemente en un contexto progresista para la mujer (integración laboral, protagonismo social...), refuerza de hecho la sumisión ante la fuerza y la habilidad del hombre" (Ramírez 98). Al teórico le molestaba, la constante trama repetida en la que Mary "noticias" dependía de la ayuda del apuesto desconocido Bruma, para resolver los misterios. Ese tipo de trama tan confortable y segura, pese a sus guiños trepidantes, era lo que Juan Antonio Ramírez veía como el "perfecto ajuste de esta concepción a una determinada mentalidad femenina" (98) que quedaba demostrada por la "fortuna de la colección" (Ioo) que sobrepasaba el año setenta y se exportaba a Francia. Es decir, las historias de la periodista independiente estaban marcadas por su relación con los personajes masculinos de los que dependía emocionalmente. En ese punto tiene razón: la masculinidad marcando las estructuras de poder todavía estaba muy anclada en la sociedad, pero el cómic también mostraba un personaje femenino profesional con libertad de movimiento que se proyectaba en la sociedad de forma pública como periodista. Era un personaje además dibujado por una ilustradora mujer lo que reforzaba la idea de reivindicar otras profesiones y posibilidades vitales. Antonio Martín, en su artículo de 20IO, también destaca esta contradicción entre lo afectivo y lo profesional: "En la España desarrollista de los años sesenta/setenta, tanto la modosa hija de familia como la universitaria continúan aspirando, más que nunca, al amor y a realizarse en el matrimonio". Es decir, el matrimonio se proyecta como aspiración vital superior, pero como indica Antonio Martín: "las lectoras se han vuelto 'modernas' y leen colecciones que mezclan en sus argumentos las nuevas aspiraciones de la mujer con la llamada a sus más elementales necesidades sentimentales".

Cabría añadir que "esas necesidades sentimentales" que destaca Martín estaban marcadas por un paternalismo que quería limitarlas, aunque permitía proyectar otro tipo de feminidad más libre e independiente. La portada de la aventura de Mary "noticias" "Buena pesca" lo confirma. En su lado izquierdo vemos que la revista juvenil femenina forma parte de la colección Heroína (del sello IMDE), cuesta 2 pesetas, es del año I962. La periodista está en su habitación y la sombra de un hombre acecha en la 
terraza. Las lectoras pueden imaginar que es Bruma, o tal vez un atacante peligroso. Aunque el título de "buena pesca" deja abierta la imaginación. Lo sugerente son las transparencias del camisón de Mary y sus uñas y labios pintados que proyectan una mujer independiente y sofisticada, copiando el modelo del cine francés y estadounidense. Solo el análisis de todas las portadas, 484 números ordinarios que están escaneadas y accesibles gracias a la ficha de Tebeosfera, daría pie a un largo ensayo sobre la representación de la femineidad de la protagonista, su relación con los personajes masculinos, la construcción de posibles tramas y pautas sociales representadas, y la primera percepción de las lectoras al enfrentarse a lo que sugieren los títulos y las ilustraciones de las portadas.

En dichas portadas vemos escenas sensuales donde aparece Mary con ropas vaporosas, peinados y complementos a la moda. También hay escenografías sugerentes que denotan una vida glamorosa donde Mary es la protagonista en fiestas variadas con traje largo, o en una exposición de arte cubista donde se ve a un atractivo artista. La realidad de los deportes motiva también sus propias tramas, y así aparece en la meta de una pista de esquí, o en un campeonato de tenis. Es decir, Mary se construye como protagonista femenino de la clase media alta que disfruta de todo tipo de eventos, tanto culturales como deportivos. A esto se suma la posibilidad narrativa de los viajes y también veremos a Mary en góndola veneciana, o con un elefantito en la India. El perfil de periodista le otorga la libertad de movimiento y le permite vivir aventuras trepidantes que harán las delicias de sus lectoras (fig. I).

Terenci Moix, en su Historia social del cómic de 1968, destacaba que Mary "noticias" es una periodista que "convierte el triunfo de la clase media en una exigencia de sublimación por parte de la clase trabajadora" (I98). En su caso Moix interpretaba a las posibles lectoras fascinadas en las tramas de la periodista Mary como a las mujeres de la clase trabajadora que trabajaban en las fábricas y que verían el periodismo como "un sueño tan lujoso como para la oficinista el de ser actriz de cine" (198).

Pero para Juan Antonio Ramírez ese intento de "crear protagonistas fijas femeninas en los años de estabilización" termina "en el fracaso" (IO2). La problemática de lo que denomina la "verosimilitud" vigente del género se enfrenta a una realidad paralela de una sociedad que todavía necesita evolucionar hacia la libertad real. Por eso su conclusión que el mismo denomina "apresurada" deja espacio para la autocrítica y la reflexión. El estudioso es consciente en 1975 de que "la mujer real, histórica, de carne y hueso, es el trasfondo de la historieta femenina y de sus derivados" (Ramírez 234-235). La mujer real es por lo tanto "un punto móvil que se acerca o se aleja de la ficción" (235). Plantea incógnitas sobre el impacto de estos modelos de mujer que representan los cómics para chicas y el tipo de 
sistema social que perpetúan: "Si hay un público femenino que consume mentiras ¿por qué echar la culpa a las mentiras mismas? ¿Y por qué a las inocentes consumidoras? La alienación de la mujer no es el problema de los tebeos" (235). Sin embargo, había que reconocer que "el tebeo femenino" era "un excelente campo para estudiar algunos mecanismos básicos" que regían "el funcionamiento de la precaria sociedad de masas española" de aquel momento (236). Las tramas de Mary "noticias" evolucionaron hacia un exotismo vital que era inalcanzable para la realidad de sus lectoras. El mundo que representaba no era factible, ya que casi nadie viajaba al Japón, a Venecia o a la India. Pero aunque fuera imposible y distante, servía como válvula de escape para la imaginación de las mujeres lectoras que se ponían en su lugar y leían esas historietas como espacio de entretenimiento fantasioso.

Sin embargo, el eje narrativo de las tramas se adecuará a los nuevos perfiles de lectoras que buscarán historias de corte realista. Los modelos de la mujer europea irán cuajando en la estética del cómic. Esther fue un personaje femenino que marcó a varias generaciones de lectoras y que aparece en I97I de la mano de Purita Campos. Esta dibujante ganó en 2016 el Premio Honorífico del Colectivo Autoras de Cómic y en el blog de la propia asociación explicaban sus méritos: "por su labor incansable y por pertenecer a una generación de trabajadoras y trabajadores del tebeo cuyo lugar en la historia de nuestro cómic hemos de reivindicar" (Autoras de Cómic). Previamente le habían concedido en 2009 la Medalla de Oro al Mérito en las Bellas Artes y, en 2013, el Gran Premio del Salón Internacional del Cómic de Barcelona por toda su trayectoria.

Campos se define a sí misma como dibujante, ilustradora y pintora barcelonesa, que se formó en Bellas Artes y en Arte Dramático como actriz. Comenzó su carrera siendo adolescente y dibujando figurines y patrones de moda para una editorial. Ella misma lo explica en 201 II en la presentación que hace al libro de divulgación sobre el tebeo femenino. Fue una casualidad la que le llevó a la editorial Bruguera, porque Purita Campos no tenía intención de dibujar tebeos, pese al talento que ya mostraba dibujando y enmarcando bailarinas clásicas que vendía en las perfumerías. El hermano de Purita Campos conocía a Manuel Vázquez, autor de las historietas de la Familia Cebolleta, Las hermanas Gilda y Anacleto agente secreto, y este recomendó que la autora presentara su trabajo a la editorial. Esta se presentó con su carpeta de obras, que eran en su mayor parte trabajos de la Escuela de Bellas Artes, y tuvo su primera oportunidad profesional: "Nos recibió Victor Mora, que cogió mis trabajos y entró a otro despacho. Salió y me dijo: 'Mañana ya puedes empezar'. Comencé realizando dibujos que ilustraban artículos y textos de sus revistas. Estaba contenta porque me pagaban por lo que hacía" (Campos 3). 
Purita Campos hizo ilustraciones para las portadas de Sissi y Blanca, y un día el director de Bruguera le pidió que hiciera un serial; de este modo explica cómo nació Mary Dunning su primer tebeo (3). El talento de Purita Campos se internacionalizó y empezó a tener encargos para Inglaterra, donde se destacan los que hizo para la revista Princess Tina. Sobre muchas de esas colaboraciones que gráficamente conectaban muy bien con el estilo de los setenta, la autora tiene una interesante opinión: "surgieron otros encargos, como dibujar historietas de tres o cuatro páginas que no me gustaban demasiado porque siempre eran lo mismo: chico conoce chica y se enamoran" (3).

La temática romántica saturaba el mercado del tebeo, y las historietas breves no permitían profundizar en la problemática de los personajes, por lo cual aburrían a la ilustradora. Sin embargo, en 1971, surgió la oportunidad de hacer el serial Patty's World para la revista británica Princess Tina. El guión era de Phillip Douglas y como bien explica Purita Campos "la serie tuvo tanto éxito que se vendió a toda Europa" (4). La propia editorial Bruguera compró la serie en 1974 y la tituló Esther y su mundo y la fue publicando en "las revistas Lily (1974), Jana (1983), Pecosa (1986) y TBO (1988)" (Campos, Presentación 4). Retomando el éxito de la serie que marcó a las niñas de los ochenta, en 2006 aparecen Las nuevas aventuras de Esther con guión de Carlos Portela, en las que Esther es una madre soltera con una hija adolescente y tiene una vida ajustada a las nuevas realidades de la sociedad contemporánea. Estos rasgos ofrecen paralelismos divergentes entre la madre y la hija. El mundo ha cambiado y Esther ha tenido que transformarse en una luchadora para sacar adelante a una hija que no sabe valorar los esfuerzos de su madre.

Gracias a la serie de Esther y su mundo, que tantos éxitos cosechó en los setenta, los holandeses encargan a Purita Campos que dibuje en 1975 al personaje de Tina, trabajando con los guiones de Andries Brandt. La serie aparecerá en España con el nombre de Jana y dará lugar a una revista. La revista Jana, que apareció en 1983 y se autodenominaba "la mejor revista semanal para chicas", se vendía en los kioscos y su primer número costaba 65 pesetas, y en sus portadas aparecían ilustraciones de chicas que se parecían a los diferentes personajes de las historietas. A partir del número 45 las ilustraciones de chicas pasaron a ser fotografías de niñas de entre nueve y doce años. En su primer número la portada anunciaba que en su interior había cinco grandes aventuras, entre ellas la de Jana, la de Paula y la de Yoko Tsuno.

Las historietas seriadas de Jana eran las que primero aparecían. Jana era una joven modelo que solía solucionar todo tipo de misterios y vivía diferentes aventuras por los lugares por donde desfilaba. Estas historietas de trazo realista las firmaban Andries Brandt, como guionista, y Purita 
Campos, como dibujante. Andries Brandt también era el guionista de la serie de "Paula, la mujer voladora", dibujada por Redondo, que narraba las aventuras de una azafata que aterrizaba en la ciudad de Guatemoc y descubría un antiguo tesoro azteca. La historia de Paula duraba once semanas y estaba llena de todos los estereotipos posibles sobre el mundo indígena centroamericano, en la representación del indígena como ente exotizado y de sus espacios como los lugares folclóricos y pintorescos de la propaganda fotográfica turística. El personaje que acompañaba a la heroína se llamaba Morris y era un hombre blanco, rubio de ojos azules, con mucho encanto que se dedicaba a trapichear. La revista tenía además una sección llamada "El bazar de Jana", dedicada a informar a las jóvenes lectoras sobre distintos temas, entre los que había consejos prácticos sobre cómo vestirse o broncearse, o recetas básicas de cocina. Algunas veces incluían una sección del horóscopos o tests de personalidad, tratando de imitar los apartados de las revistas de modas para mujeres. También existía un apartado de intercambio de correspondencia, o concursos.

En la mayor parte de las historietas de la revista para chicas Jana que aparecen en los ochenta, predominaba una imagen artificial de la feminidad. Es cierto que las protagonistas eran mujeres independientes con gran personalidad e iniciativa, pero casi siempre su escenografía giraba en torno al universo de la moda y la belleza. Eran profesiones vinculadas al mundo del espectáculo, bailarinas, especialistas de cine, actrices y sobre todo modelos. Incluso cuando se adaptaban a la época contemporánea versiones de cuentos clásicos, como el de la Cenicienta, transformaban a su protagonista en supermodelo. Mezclaban la historia de la niña maltratada con el cuento del patito feo. La calidad gráfica y narrativa de muchas de las historias era muy limitada, parecía que sus dibujantes estaban sometidos a la producción constante y rápida, y eso no generó un espacio lector consolidado

Casi todas las niñas que leyeron estos cómics para chicas los recuerdan como algo puntual en sus vidas, un episodio de su primera adolescencia cargada de sueños sofisticados y cursis en los que los príncipes azules de antaño ahora eran productores de cine o fotógrafos de revista de modas que las descubrían. Se podría decir que, la baja calidad de los guiones de aquellos cómics para chicas, impidieron abrir un espacio de recepción femenino. Si estos cómics hubieran tenido calidad narrativa, habrían consolidado un gusto lector entre la audiencia receptora. Sin embargo, solo continuaron leyendo cómics aquellas lectoras que combinaron este espacio de cómic rosa de escasa calidad con los álbumes clásicos y canónicos de la escuela juvenil franco-belga, y los diferentes comics vanguardistas experimentales de adultos, tanto europeos como norteamericanos. Es lamentable que aquellas revistas de cómics para chicas no tuviesen una verdadera vocación 
expresiva dentro del medio y sólo pretendiesen ser un objeto de consumo que repetía estereotipos de género, jugando a un falso feminismo. No había una preocupación real por desarrollar tramas que representasen sociedades igualitarias o expresaran posibilidades certeras de empoderamiento de los personajes femeninos. Aquellas revistas de los ochenta pudieron ser la rampa de despegue de un imaginario gráfico innovador que formase lectoras, pero desgraciadamente se conformaron en muchos casos con los discursos folletinescos de la peor tradición rosa de sus antecesoras.

Las autoras abordadas aquí, Isabel Bas Amat, María Pascual, Carmen Barbará y Purita Campos, nacieron a lo largo de la década de los treinta del pasado siglo, y en su vida profesional ofrecieron propuestas creativas donde lo femenino funcionaba como eje de representación cultural. El peso del discurso franquista estaba muy presente en el contexto de su formación intelectual. Crecieron en plena posguerra y tuvieron que interiorizar las pautas sociales de una dictadura que discriminaba a la mujer y la consideraba un ser inferior y dependiente de los hombres. En ese contexto educativo y social, sus trabajos sobresalen por priorizar a la mujer como temática protagónica. Eso ya presenta un avance significativo porque generó un espacio lector de niñas y mujeres que se sentían identificadas o proyectaban sus propios anhelos y ensoñaciones. En un entorno editorial en el que los hombres eran los que marcaban las tendencias, ellas establecieron sus propias voces y estilos. Esperar que hubieran sido más subversivas en las circunstancias en las que crecieron resultaría anacrónico. Se desarrollaron en entornos masculinos y tuvieron que adaptar sus discursos creativos a una sociedad franquista que las supervisaba y controlaba su creatividad. Pese a todo, con sus personajes abrieron espacios para que la imaginación de las mujeres fluyera y encontraran consuelo y alegría lúdica y sofisticación trepidante en una sociedad gris y profundamente machista.

Las líneas investigadoras que profundizan en el espacio de los cómics femeninos españoles y sus orígenes tienen varios retos fundamentales que afrontar. Por un lado, está la necesidad historiográfica de recuperar a las autoras y estudiar su trayectoria en el contexto de las realidades sociales que vivieron. Por otro, deberán desarrollar un análisis de contenido que reflexione sobre la recepción del momento y las diferentes miradas teóricas que se han ido articulando en la construcción de lo femenino y la impronta que dejaron esos tebeos en la cultura popular de varias generaciones de lectoras. Son esos parámetros los que, tomando una mirada historiográfica con la meticulosidad descriptiva de la analítica, permitirán recuperar un corpus clave e inmenso que todavía dormita en archivos y colecciones privadas.

University of Iowa 
NOTAS

I Muchas de mis reflexiones sobre la importancia de las voces femeninas estadounidenses y su impacto están recogidas en el capítulo 7 de mi libro, Diez ensayos para pensar el cómic (2017).

2 En mi libro El comic hispánico (2003), combino el estudio panorámico e historiográfico con el análisis detallado de historietas y viñetas siguiendo el modelo de Umberto Eco.

3 Antoni Guiral, en su genealogía sobre la mujer historietista en el cómic español para el catálogo Presentes, explica como la editora Consuelo Gil "tuvo la inteligencia de no ceder a la presión" del franquismo y "apostó por un contenido laico, dirigido básicamente a publicar textos e historietas de humor y de aventuras, y con colaboradores tan excepcionales como Jesús Blasco, Emili Freixas, Serra Massana, Castanys, Mercé Llimona o Carmen Parra" (I2). Por otra parte, durante la posguerra y el desarrollismo, fueron surgiendo otras revistas como Bazar, Florita, Mariló, Merche, Sissi y Blanca que, como bien indica Antoni Guiral, siguieron la estela de Mis Chicas.

4 En I968, Terenci Moix publicó un libro de corte generalista sobre los cómics en los que dedicaba un capítulo a la revista Mis chicas. Por otra parte Antonio de Mateo en 2002 escribió sobre la labor de Consuelo Gil y sus colaboradoras en el catálogo de la Biblioteca de Nacional dedicado al semanario infantil Chicos.

5 La ficha de la palabra tebeo en el espacio enclave.rae.es indica ejemplos de uso que se remontan a 1966.

6 En los estudios del cómic, término referido a la historia que se desarolla en una sola página y que concluye con una última viñeta de gag de humor.

OBRAS CITADAS

A u T o RAS DE Có M I C. "Premio Honorífico 2016: Purita Campos, una incansable trabajadora del cómic." Blogspot. Colectivo Autoras de Cómic. 30 diciembre 2016. Web. Acceso Junio, 2018.

B AR B A RÁ, CARM E N. “Buena pesca." Mary “noticias” I68 (I962): Portada. Barcelona: Iberomundial Ediciones. Tebeosfera S. pag. Web.

barrero, Manuel, antonio moreno y josé manuel rodríguez. "Mary 'noticias'(1962-1971)." Tebeosfera 2008. S. pag. Web.

в AS AмAт, IS Aв EL. Ana-Emilia y su familia. Tebeosfera. 1967-20I8. S. pag. Web. BAS, ISABEL y ELISA M CCAULAND. "Isabel Bas Amat, una mujer en el TBO." Tebeosfera 3.2 (2017): S. pag. Web.

B E RNÁNDEZ, RUTH. Las chicas son guerreras: El cómic femenino de los 70 y 80. Mallorca: Domen, 2018. 
CAmpos, purita. "Presentación de El tebeo femenino de Marisa Herreros

Mediavilla." Ed. Alberto Santos. Madrid: Imágica Ediciones, $201 \mathrm{II}$.

CAMPoS, PURITA, Y ANDRIES BRANDT. Jana. Barcelona: Glénat, 2008. Biblioteca

Digital de Aranjuez, 2008. S. Pag. Web.

CoSSE, I SA B E L a. Mafalda: historia social y política. Buenos Aires: Fondo de Cultura

Económica, 2014.

“Tebeo." Diccionario de la Lengua Española. Vigésima primera edición. Madrid: Real Academia Española, 1992.

e co, u m Be Rt o. Apocalípticos e integrados. Barcelona: Lumen y Tusquets, 1995.

GAyÁ, CATA lina. "Carme Barbará: 'Hasta la censura se metió con Mary 'noticias." El

Periódico. (2014): S. pag. Web.

GUIRAL, ANTONI. "Aproximación a una genealogía de la mujer historietista en el cómic español: de los inicios al Boom de las revistas." Presentes: Autoras de Tebeo de ayer y hoy. Eds. Elisabeth McCausland, Carla Berrocal, Antoni Guiral y Ana Merino. Madrid: AECID, 2016.

JIMÉNEZ, JESÚs. "Chicas de cómic, un homenaje a las heroínas de los tebeos." El cómic en RTVE.es. (2014) S. pag. Web.

JOHNSON, ROB ERTA, y MAITE ZuiB IARRE, E DS. Antología del pensamiento feminista español, 1726-20II. Madrid: Cátedra, 2012.

m c Cau land, E lis a. "El trazo lúcido de Núria Pompeia." Pikara Online Magazine (2017): S. pag. Web.

mate 0, Anto Nio De. "Consuelo Gil y sus colaboradoras: Aportación femenina a sus revistas y empresas editoriales." Chicos. Semanario Infantil. 1938-1956. Madrid: Ediciones Sinsentido, 2002. 35-46.

MaRtín, A nT onio. "Desde la historieta clásica para niñas a Mary 'noticias..” Tebeosfera 2.6 (2010): S. pag. Web.

MARTín GAITE, CAR ME N. Usos amorosos de la postguerra. Barcelona: Anagrama, I987.

ME DiNA, G U IL L E M. Chicas de cómic. Barcelona: Glenat: 20 IO.

M E RIN O, ANA. El cómic hispánico. Madrid: Cátedra, 2003.

—. Diez ensayos para pensar el cómic. León: Universidad de León y Eolas Ediciones, 2017.

-. "Women in Comics: A Space for Recognizing Other Voices." The Comics Journal 237 (200I): 44-48.

M OIX, TERENCI. Historia social del cómic. I968. Barcelona: Bruguera, 2007.

MUÑ OZ, JO SUNE. "Breve historia del cómic femenino español: autoras, obras y prejuicios." Actas del I coloquio hispano-ruso sobre mujer y literatura. San Petersburgo: Universidad de San Petersburgo, 20II. 2-24.

RAmíre Z, JU AN AN to nio. El cómic femenino en España. Madrid: Cuadernos para el Diálogo, I975. 
ANEXOS

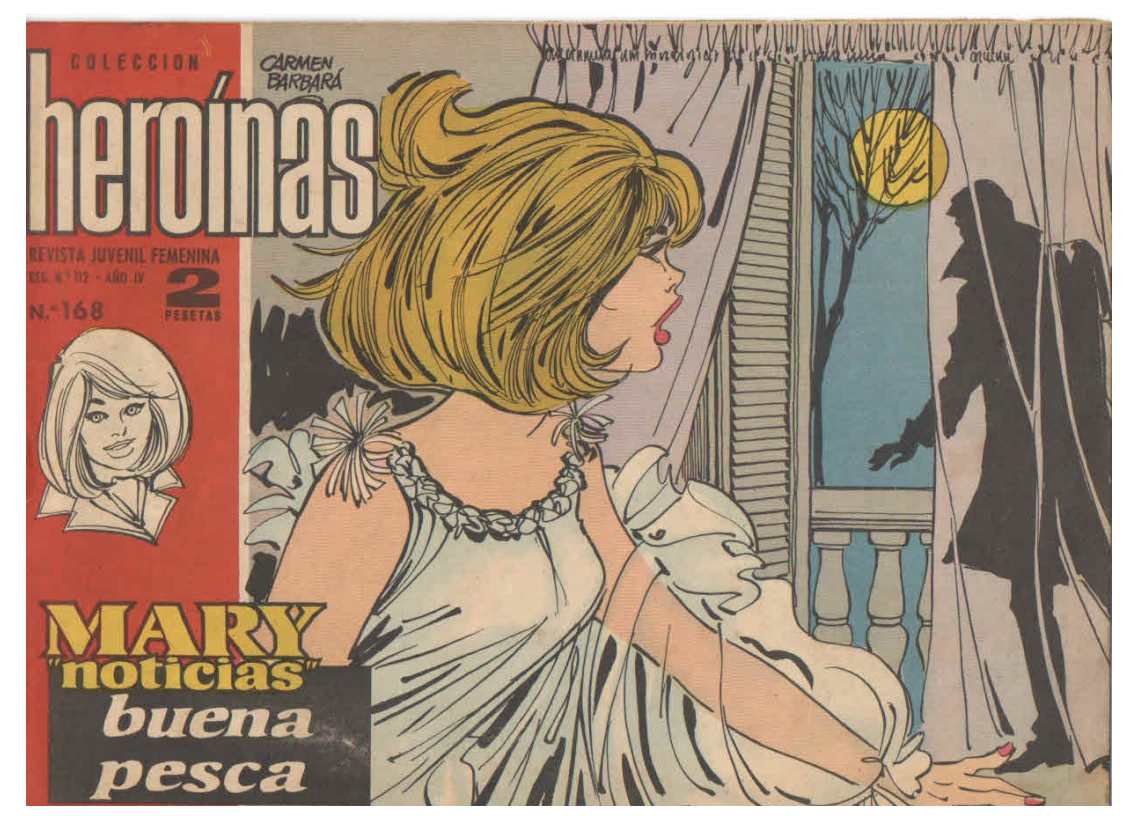

Figura I 